This item was submitted to Loughborough's Research Repository by the author.

Items in Figshare are protected by copyright, with all rights reserved, unless otherwise indicated.

\title{
Alternative revenue streams for centrally funded sport governing bodies
}

PLEASE CITE THE PUBLISHED VERSION

https://doi.org/10.1080/19406940.2017.1387587

\section{PUBLISHER}

(c) Taylor \& Francis

\section{VERSION}

AM (Accepted Manuscript)

\section{PUBLISHER STATEMENT}

This is an Accepted Manuscript of an article published by Taylor \& Francis in International Journal of Sport Policy and Politics on 06 Feb 2018, available online: https://doi.org/10.1080/19406940.2017.1387587.

\section{LICENCE}

CC BY-NC-ND 4.0

\section{REPOSITORY RECORD}

Berry, Rostron, and Argyro Elisavet Manoli. 2019. "Alternative Revenue Streams for Centrally Funded Sport Governing Bodies”. figshare. https://hdl.handle.net/2134/26801. 


\section{Alternative Revenue Streams for Centrally Funded Sport Governing Bodies}

Rostron Berry $^{\mathrm{a}}$ and Argyro Elisavet Manoli ${ }^{\mathrm{a} *}$

${ }^{a}$ School of Sport, Exercise and Health Sciences, Loughborough University, Loughborough, UK

In a world of ever-increasing focus on Government spending as a result of recession-induced austerity measures, the current Government of the United Kingdom has clarified its intention to share and ultimately transfer the burden of funding to those sports that currently enjoy government support. Outside the sports that, due to their wide commercial and broadcast appeal are able to derive significant revenues, it will become necessary for national governing bodies (NGBs) to cast the net wide in search of consistent, reliable methods of generating revenues that satisfy broader stakeholder aims whilst maintaining focus on their core responsibilities of sport development, encouraging participation and driving performance. In order to unpick this process, interviews were undertaken with senior officials from non-commercialised NGBs to better grasps the current situation and what steps are being taken to secure funding with further exploration of the impact of these new streams. Using Pfeffer and Salancik’s Resource Dependence Theory and Markowitz's Portfolio Theory, this study examines the revenue streams currently explored by the NGBs, as well as their associated benefits and pitfalls. Through this research, it was found that the applicability of each stream was largely dependent on the unique characteristics of each body. Size and demographics of membership or participants, the degree of formality of participation, local or regional importance of the sport and commercial appeal to potential sponsors and partners, all drove the particular mix of revenue streams achieved by NGBs, making generalisation or the creation of a usable, common template difficult as a result.

Keywords: Government policy; UK policy; sport NBGs; austerity; sport governance; sport policy; 


\section{Introduction}

In its policy document, Sporting Future: A New Strategy for an Active Nation (UK Government, 2015), the UK Government’s Department for Culture, Media and Sport ${ }^{1}$ (DCMS) outlines a shift in the vector of sport policy, announcing a refocus away from purely boosting participation numbers to making funding decisions based 'on the social good that sport and physical activity can deliver...and how sport can have a meaningful and measurable impact on improving people’s lives’ (UK Government, 2015, p. 6). The DCMS has outlined five outcomes that will be used as yardsticks to redefine and measure what success looks like for sport in the UK, using the new Active Lives survey to replace the previous Active People Survey. The policy document extends the previous focus on Olympic and Paralympic sport performance to non-Olympic sports in order to broaden the potential reach and social outcomes. One of these outcomes, that of Economic Development, espouses making the sector 'stronger and more resilient...reducing the reliance on government public funding' (UK Government, 2015, p. 53), further reinforced by the 2015 Autumn Budget Statement (UK Government, 2015) which shows that the total UK spending on sport represents only $0.3 \%$ of the total budget spent, while remaining frozen in gross terms at $£ 1.1$ billion p.a. for the next 5 years but still representing a 5\% reduction in real terms over that period. An antithesis then can be noted between the Government's plans to reduce the funding while maintaining or even increasing their influence and expected outcomes.

It is these two facets of policy, that of extending to non-Olympic sports, and increasing the proportion of non-public money in their funding, as well as relevant academic research, such as Green and Collins' (2008) and Collins' (2010) work on how

\footnotetext{
${ }^{1}$ The term 'government' in this study is referring to the current Conservative Government of the UK (2010-today).
} 
uncertainty of government policy impacts on sustainable development in sport, that have guided this research. The response to increasingly stringent public funding criteria has attracted academia’s interest before, with studies (Garrett, 2004) suggesting that a variety of revenue streams might be a healthy solution. In a contrasting position, the balance of elite performance versus mass provision can be lost as a result of less centralised funding (Sam, 2009). This redirection from the DCMS may also be of concern to niche sports that do not enjoy a large participation base or mainstream media popularity (Turner, 2013), since, in spite of private sector spending on sport sponsorship rising from £242million p.a. in 1997 (Carrigan \& Carrigan, 1997) to £798million in 2010 (Mintel, 2011), Football and the Olympics attract 80\% of that amount. When Cricket and, Rugby Union are added, that share rises to 91\% of all new sponsorship deals, demonstrating sponsors’ strong sporting preferences.

In short, changes in the way sport is funded will be thrust upon a number of governing bodies, yet existing research has failed to suggest much in the way of alternatives outside of the sale of media rights and sponsorship (Jensen \& Cobbs, 2014; Herrmann, Kacha \& Derbaix, 2016), both of which are more problematic for smaller or non-commercialised sports. As a result, and due to this lack of relevant studies particularly on non-commercialised sports, we have yet to identify and suggest potential directions in which sports that do not benefit from large media-rights funding infusions should look to in order to diversify their funding streams away from public-sector money.

This study aims to address this gap by investigating alternative funding opportunities for non-commercialised sport NGBs, and thus highlighting the characteristics, benefits and drawbacks associated both with these and central funding. In order for this to be conducted, the focus will be drawn on the funding of forty-six sports (see Appendix A) 
that received funding through Sport England’s 2013-2017 Whole Sport Plan (Sport England, 2013), while excluding those that receive a large proportion of their funding through the sale of media rights (Football, Cricket, Rugby Union, Rugby League, Tennis, Golf and Cycling). In order for alternative revenue streams to be identified, the role of Government's financial support in sport and the characteristics of centrally funded governing bodies will be investigated, as well as the process and potential drawbacks faced by sport NGBs with regards to funding. Additionally, all revenue streams currently used by the governing bodies will be explored and examined in regards to their potential benefits and drawbacks.

\section{Theoretical background}

The ability of an organisation to attract funding is determined by its potential to generate financial returns to its funders. However, sport and its promotion is of central concern in countries such as the UK because of its impact on health, wellbeing, personal and social growth and economic development (HM Government, 2015, p. 72), which combined with its elements of non-rivalry and non-excludability, would not incline the free market to provide (or fund) it $^{2}$ (Sloman, 1994). It is these factors that create the rationale behind government intervention and as a result, government funding is currently the key element of sport provision in the UK. Appendix B shows the major elements breakdown of Sport England funding for the period 2013-2017, that will total $£ 493$ million.

This significant investment from the UK government has raised an extended debate

\footnotetext{
${ }^{2}$ It is suggested that the two characteristics that make goods and services worth funding and trading in the market are rivalness ("my use of the good leaves less for you”) and excludability (“I can keep you from using this good”) (Fisher, Turner \& Morling, 2009, p.7).
} 
over the expected and actual outcomes of public money spending on sport. One of the main arguments in this debate is the question of mass participation versus elite performance, and the discussion over of the ability of successful elite sport to promote mass participation and the added-value of fringe benefits of national prestige and the associated feel good factor (Green, 2006, 2007; Grix \& Carmichael, 2012). Other benefits of sport with specific reference to major events, such as hosting or achieving success in the Olympic Games (Grix \& Houlihan, 2014) mooted as evidence for government intervention and support include urban regeneration (Coaffee, 2008), legacy from volunteering at events (Doherty, 2009) and of participation legacy (Ramchandani, Davies, Coleman, Shibli, \& Bingham, 2015). It is worth acknowledging that all this evidence has stirred a debate in the academic community with various and often contradicting arguments being made regarding the extent to which they can in fact materialise (Hall, 2006; Toohey, 2008).

Government funding and intervention is also believed to be a catalyst to achieve governance standards more commensurate with modern business practices, having the added benefit of increasing the attractiveness of the modernised and better governed sport organisation as a commercial partner, while promoting in this way the future of the sport (Houlihan \& Green, 2009). On the other side of the debate, the question raised is whether national sport or large event financing sucks resources away from grassroots sport provision (Kavetsos \& Szymanski, 2009), even if there is a clear participation legacy aim of the event. While opinions on this matter differ, we can argue that the rationale behind government involvement in sport is well researched (Grix \& Carmichael, 2012) and the track record of UK government funding in sport is clearly evident (DCMS, 2013). Nevertheless, with the recent UK Government policy documents suggesting that a decrease on public funding is afoot, questions are posed 
regarding the effects of this significant dependency of sport organisations from the Government, while at the same time raising concerns regarding the future of these sports unless alternative sources of funding are found.

\section{Single Source or Government Funding Dependency}

The question of finding the optimum blend of funding methods for any organisation has been investigated using Pfeffer and Salancik’s Resource Dependence Theory (1978) that highlighted the often reciprocal dependency organisations might have and how this may exert external controls or direction on an organisation. RDT characterizes the organisation as an open system, dependent on contingencies in the external environment that influence its behaviour. According to Hillman, Withers and Collins (2009), RDT recognizes the influence of external factors on organisational behaviour and, although constrained by their context, organisations can act to reduce their dependency. Central to these actions is the concept of power, which is the control over vital resources (Ulrich \& Barney, 1984), and the organisations' attempts to reduce others' power over them, or even to increase their own power over others.

When an organisation is heavily dependent on the government, the environmental dependency is one of the most difficult to control according to Aharoni, Maimon, and Segev (1981) and Lester, Hillman, Zardkoohi and Cannella (2008), due to the heterogeneous interests of different agencies and political decision makers. What is then expected and almost feared is that this increased dependency will lead to a loss of autonomy on the organisation's strategy and subsequent management decisions. This autonomy could then decrease further if the proportional magnitude of the resource input increases, if the importance of government resources for the organisation increases, or if the presence of alternatives for financing decreases (Pfeffer \& Salancik, 
1978; Kramer, 1981). The pitfalls of such a high reliance on Government funding, and thus a lack of autonomy, is the design and implementation of a policy that is 'dictated' from the Government to the organisation (top-down), rather than created through the demands and needs of the community (bottom-up) as Carey and Braunack-Mayer (2009) argue. This could potentially lead to a decreased focus on community provision of non-profit services, as well as to an increased difficulty of maintaining the strength of effort within the community (Van Brummelen, 1993). Consequently, tensions can arise between the funded organisation and the funder when expectations are not aligned (Krashinsky, 1990; Anheier, Toepler, \& Sokolowski, 1997). Increased financial dependency and the consequent lack of autonomy in strategy development have been also linked with changes in organisational characteristics and priorities, such as refocusing from fund raising to financial monitoring and advocacy (O'Regan \& Oster, 2002) and altering the management and board composition of an organisation to align to Government ideals (Miller, Kruger, \& Guass, 1994).

In the context of this study, research shows that increasing external revenues such as public subsidies can have an impact on a sport club’s autonomy and subsequent strategy design and implementation, as examined by Horch (1994) in Germany and by Vos et al. (2011) in Belgium. However, and regardless of this seemingly negative effect, the government support and dependency in voluntary sport organisations in countries such as Canada has been gradually increasing (Slack \& Hinings, 1992; Lasby \& Sperling, 2007), along with the government pressures for a return for this investment. In other words, the dependency created by providing funding for these sport organisations, has allowed the respective Governments to directly impact behaviours and decisions made for the supported organisations’ strategy and practices, which in turn could lead us to question the overall independency and focus of these organisations’ strategy. 
In Slack’s and Hinings' (1992) study, this dependency is presented in bright colours, suggesting that many of the changes or improvements that occurred as a result of it benefitted the organisations significantly. The support provided to the sport organisations by the government was paired with pressure for change and for particular results to be achieved. Over the years, these expected results (or return to the investment) have been gradually changing, according to Slack and Hinings, from a relatively broad concern with the promotion and development of all levels of sport, to a specific focus on the production of elite athletes and subsequent international sporting success. This has also resulted in additional pressures to implement internal changes while often dictating requirements and prescribed practices for the dependent sport organisations.

Such a study on the effects of UK Government's support and the increased dependency of the national non-commercialised sport NGBs has yet to be conducted, limiting our understanding of the characteristics and potential shortcomings of their relationship. However, if the status-quo of government or in general single-source funding is deemed, on balance, to be unattractive, and with the role of Government set to diminish, sport organisations must therefore investigate other sources that might provide the revenue needed to maintain and grow their provision and thus aid development of their sport.

\section{Multiple Alternative Revenue Streams}

The question of how wide the net should be cast can be studied using Markowitz's Portfolio Theory (1991) that ostensibly deals with investor decision making processes leading to investment for funding, but most usefully in the context of this study, deals with the interchangeability of utility and rate of return that can be taken into context, 
replacing investment mechanisms with sources of funding. Portfolio Theory is focused on the analysis and understanding of the funders and their choice between risk and return on investment, while probing questions on the decisions made by the funded organisation to accept the said funding or not. In other words Markowitz's analysis suggests that the funded organisation has also to evaluate the number and portfolio of investors they will accept funding from. This was expanded upon not long after to conclude that neither complete dependence nor complete diversity of income was able to completely reduce the variability of income (Kingma, 1993).

Whilst literature has been prolific in critiquing models of organisations that rely too heavily on one source of funding, with Bielefeld (1992) in particular highlighting that greater fund heterogeneity reduces the vulnerability of an organisation, the opposite extreme of excess diversity in funding also creates headwinds for organisations. For example, Tolbert (1985) found that an increasing number of revenue streams led to increasing complexity and required a larger number of administrative bodies to deal with that complexity, driving costs higher. Moreover, when Hardina (1993) and Froelich (1999) focused on the problems experienced by multi-stream funded organisations they identified issues such as external sources exerting pressure to influence choice of strategy or aim, thereby limiting the ability of the organisation to act in the interests of the community it serves, and thus compromising its representativeness.

When one of these funding sources is the Government, Brooks (2000) suggests that there may be unconscious competition between the funding sources, increasing the pressure the funded organisation is under, and potentially crowding out other funding avenues, especially private philanthropy. This idea that public funding might crowd out private funding has in fact been debated for almost three decades (Aschauer, 1989), 
with numerous contradicting views being expressed.

In a sport specific context, it is argued that this crowd out effect does not exist either between public funding and commercial income or between commercial and voluntary income (Enjolras, 2002), suggesting that sport organisations can attract multiple different sources of income simultaneously. In fact, the potential to crowd-in different sources of income, such as donations and sponsorship, through the attraction of public subsidies was supported through the study of non-profit sport clubs in Germany (Wicker, Breuer, \& Hennigs, 2012). Even though the available studies examining the interaction between different sources of income in the sport environment focus on nonprofit sport clubs in Germany (Wicker \& Breuer, 2011; Wicker et al., 2012) and Belgium (Vos et al., 2011), which receive minimum public funding, there appears to be no evidence suggesting that a crowd out effect exists between Government funding and other sources of income for sport organisations.

If such a phenomenon applies in the UK sport context, then a question can be raised on the reasons behind national sport organisations' heavy reliance on Government funding (Taylor \& O’Sullivan, 2009). The answer to this question could be the heterogeneity of sport organisations, especially with respect to their aims, stakeholders and participants, which is highlighted as an explanatory factor for non-mainstream sport's difficulty to access funding (Garrett, 2004; Turner, 2013). Funding mechanisms often seek standardisation of governance, targeting sports that espouse the values associated with state funded agencies in order to initialise performance related funding on organisations that cannot be compared in character or structure, thus making minor sports ineligible. At the same time, according to Weisbrod, Handler and Komesar's (1978) Median Voter Theorem, Governments seek to support the mainstream, such as sports, since it can potentially increase their popularity within the voting population. 
This further underlines the need for additional research to be conducted on noncommercialised and less popular sports, which might be facing difficulties in attracting such support and revenue.

Whilst there are a number of revenue streams available to sport governing bodies, be it selling of media rights, philanthropy, merchandising or internal revenue generation through charging of user fees, the avenue theorists most widely apply is the attraction of sponsors. Research has focused on identifying factors that affect the attractiveness of propositions to sponsors as virtually no corporate donor will view it as a philanthropic undertaking but will have the return on investment as their major marker of success and judge opportunities on criteria to ensure the highest return possible (Jensen \& Cobbs, 2014; Manoli, 2015; Herrmann et al., 2016). Copeland (1996) also found that most sponsorship arrangements were far from equitable, yet this does not dissuade corporations from spending resources to find a perfect event to match their image as well as researching demographic and psychographic profiles of participants (Irwin, 1995; Pappu \& Cornwell, 2014). This helps in gauging the level of brand exposure, quality of the sport concerned, exclusivity arrangements and quantity and quality of broadcast exposure (Wilson, Westberg, \& Henseler, 2011; Manoli \& Hodgkinson, 2017).

In summary, academic literature has examined government funding of non-profit organisations in general and sport in particular, discussing its associated drawbacks and benefits, while suggesting that multiple sources of income should be preferred in order to avoid high dependency and the associated risks, but are nonetheless challenging to acquire. Thus far however, research has not been able to provide insights on the impact of withdrawal of this Government funding in whole or in part, hence failing to suggest potential future directions to sport organisations that will be soon put in this difficult 
position.

This research will intertwine these existing, separate avenues of enquiry, in order to focus on the non-commercialised sport sector that has thus far been insulated from the perils of funding shortfalls by the ever present state coffers of UK Sport and Sport England $^{3}$ (backed by the UK Government), and ignored due to a lack of attractiveness by the commercial and broadcasting entities that already safeguard the position of football, rugby and cricket in the UK sporting pantheon. This study will also attempt to examine the characteristics and potential drawbacks of this high dependency of noncommercialised sports governing bodies from the Government, in an attempt to highlight the currently unknown aspects of this relationship. Finally, it shall attempt to uncover lessons learned by governing bodies that have been successful in making progress to more sustainable, less dependent and vulnerable models of funding, to enable a broader application across more sport NGBs.

\section{Methodology}

In order to be able to build a full picture of the processes involved in financing sporting organisations, and while understanding the important influence of the human element, data collected through in-depth, face to face interviews are examined in this study. The interviews were undertaken based on a semi-structured interview plan that was informed by the review of existing literature (found in Appendix C). This enabled the research to take the form of a cross-sectional, descripto-explanatory study (Saunders, Lewis, \& Thornhill, 2012).

The review of existing literature and areas of study highlighted a number of topics

${ }^{3}$ UK Sport is the funding body for elite sport, while Sport England deals with grassroots and amateur sports. 
that were incorporated into the interview plan. To begin with, a general picture of the organisation was sought, in order to understand the priorities and aims with regard to participation and whether it sits as a for-profit, revenue generating or not-for profit organisation. The general, existing state of funding structure of the organisation was discussed to ensure the validity of including it in the research along with implications for the body if policy shifts along the lines of the DCMS document (HM UK Government, 2015) restricting the amount of central funding. The importance of and relationship with the central Government or UK Sport and Sport England was also a topic of inquiry, along with investigating the body's experience with the processes involved in securing central funding and the associated benefits and drawbacks, if any. With regards to alternative sources of funding, topics of interest included the existing policy and procedure designed to help seek out other revenue streams, what challenges these streams present, and what benefits each might bring, along with identifying resources necessary for a successful restructuring if required.

It is important to note that the interviews were non-standardised, even if following a semi-structured form, in order to allow the freedom to allow each participant's particular experience and expertise to add to the interpretive value (Lee \& Lings, 2008). Face to face interviews were the preferred mode of discussion as these allow a greater rapport to be built along with a higher degree of trust.

The population studied comprised of 46 UK sport organisations that receive funding from Sport England or UK Sport as listed in Appendix A. For the purposes of this research, sports that benefit from large media-rights sale contracts were excluded as this is the primary source of non-government funding. These are Football, Rugby Union, Rugby League and Cricket, whilst Tennis, Golf and Cycling may also be described as commercialised sports with significant existing non-government funding in place. 
Based on the small number of number of staff employed in some of these organisations the single key informant approach was adopted, in which the individuals selected were not considered as representative of the staff of each organisation studied in a statistical sense, but were rather chosen based on their knowledge and ability to discuss the patterns of behaviour and organisational relations within the studied sample (Mitchell, 1994). In line with this approach, Senior Commercial Officers of the organisations were selected as they are most likely to have the required knowledge and expertise in the field of funding, might be able to gauge the impact of the organisations structure and hold informed views of future contingent events. They were approached to take part by emailed invitation that stated the aims of the research and the general topic of interest to be covered by the interviews. Where necessary, this was followed up with a telephone call, which resulted in representatives of 13 national governing bodies (25\% of the overall population of this study) agreeing to participate. As a result of this, a sample size of 12 interviews were undertaken between June 2016 and March 2017, covering these $13^{4}$ NGBs of varying size and characteristics. It is worth underlying that all 12 interviewees welcomed the idea of research undertaken on the topic since they expressed their concerns over the future of the represented governing bodies. A list of the questions asked during one of these interviews can be found in Appendix D. Once the interviews were completed, they were transcribed, producing 10-13 pages of single spaced text per interview, and sent to the interviewees in order for any inaccuracies or misinterpretations to be identified and for the accuracy of the interviews to be verified.

The data collected through the interviews were analysed manually through

\footnotetext{
${ }^{4}$ One individual acted as the Senior Commercial Officer for two national governing bodies. A two-part interview took place with this interviewee in order for information for both NGBs to be acquired.
} 
hierarchical thematic analysis (Zimmerman, Raisch \& Birkinshaw, 2015), which entailed a lengthy and laborious process that included a thorough and meticulous examination of the data, while colour coding the codes and themes that emerged and annotating the transcripts. This analysis allowed for the codes identified in text to be grouped under overarching themes and sub-themes (see Appendix E for key themes and illustrative quotes). All themes, sub-themes and codes were then collated on a 'thematic map’ which allowed for the specifics of each theme to be refined. For robustness, the codes and themes identified were verified through intra and inter coding agreement.

The anonymity of the interviewees and their roles will be kept throughout this study. In addition, due to the small number of individuals employed in the vast majority of the population of this study, the anonymity of the organisation - employer of each interviewee will be also protected.

\section{Findings and Discussion}

Through detail discussion on the topic of funding with the NGBs, interviewees highlighted both the positive and negative aspects of central funding and the eight alternative revenue streams they were exploring.

\section{Central Funding - Characteristics, Benefits and Drawbacks}

What was first discussed with the interviewees was the organisations' level of dependency from the Government. All 13 NGBs argued that central funding, or more specifically Sport England and to a lesser extent UK Sport, remained the most significant and important source of funding. 
reality is if they removed their funding we would be unable to continue to operate’ (Interviewee L)

As the quote suggests, this high level of dependency from this single source was often paired with an overwhelming fear of a future where this funding is withdrawn, with all NGBs underlying that central funding accounted at the time of the interviews for $80-95 \%$ of their total income. That being said, it was generally accepted that changes (Sport England funding cutback due to new policy focus) were afoot and these threatened the very existence of some governing bodies, and impacted on their ability to operate effectively, highlighting Bielefeld's (1992) belief that homogeneity of funding sources increased the vulnerability to economic shocks. As a result, it was made clear by all interviewees that governing bodies have realised they will need to make changes both in revenue generation and spending habits. Despite this, exactly what the next round of the process will look like, including any details on Sport England's objectives, remains uncertain, giving rise to fears that the funder's belief in the original objectives (increasing sport participation) may be on the wane. This may have a trickle-down effect through organisations providing services, leading to reduced quality or quantity of provision (Van Brummelen, 1993), a concern expressed by all interviewees, as the following quote illustrates:

'Our challenge is that we need to increase the income we generate as a sport... That will mean we are not able to do some of the things we are able to do now but arguably it is challenging us to find out what we really need to do as a sport and what we shouldn't be doing' (Interviewee F) 
When the process involved in attaining Sport England funding was discussed, a key issue that all governing bodies presented was that of managing or aligning the objectives of all stakeholders involved in a sport, mirroring both Carey and BraunackMayer’s (2009) and Krashinsky’s (1990) findings. Yet this was not a consistent message and was found to split the NGBs into two sides. Those few four that found themselves well aligned with Sport England's objectives believed that increasing participation was the most important goal for their organisation, yet most sports (nine out of the 13) found that their objectives were at odds with Sport England's and believed this to be a source of friction (Garrett, 2004), as the following quotes illustrate.

'Sport England is all about participation, and that's the single biggest thing to improve our sport today - so we are aligned' (Interviewee K)

'Sport England money is fantastic but sometimes there is a friction between what Sport England want and what's best for the sport. It's the members versus the increasing participation - they are contradictory demands on us. We are not an Olympic sport, so what are our KPIs away from participation?' (Interviewee C)

This disagreement and potential friction in areas of strategy presented by the majority of the NGBs aligns with the suggestions of Anheier et al. (1997) who argued that tensions can arise when there exists a difference in expectations between the funded body and the funder / government. Based on the fact that all governing bodies interviewed argued that their strategy was ultimately influenced by the strategy of Sport England, it can be suggested that, as Horch (1994) and Vos et al. (2011) advocated, increasing government 
funding can directly impact the autonomy of the governing bodies. At the same time, Slack’s and Hinings’ (1992) argument that this increased dependency paired with additional pressure for change is a positive thing for sports in terms of improvements in governance, commercial awareness and professionalism, found only few governing bodies (four out of the 13) in agreement. An explanation of that dichotomy is to be found in the specificity of the sports involved. Demographical and geographical concentration of participants, the nature of the sport itself - whether it is individual or team based, formal or informal in practising, whether it is broadcast or spectator friendly, and if there is an elite component that acts as a multiplier to mass participation to the sport (Grix \& Carmichael, 2012), all have an impact on how Sport England funding is viewed.

Connected to this was a widely held frustration with the Active People Survey ${ }^{5}$ as a method by which the governing bodies are measured and therefore held to account. This is an embodiment of the issue of which aim should be predominant for an NGB, either participation or sport development (Kavetsos \& Szymanski, 2009). Finally, the move from itemised grants from Sport England covering core costs, infrastructure and program costs, towards a system focusing solely on projects has led to concern over how core costs will be covered moving forward.

"There has been such scrutiny of what we call core costs, that Sport England call cost of opening our doors, that now Sport England are looking to fund on a project to project basis. However, as we are still a small sport we need funding to cover the

\footnotetext{
${ }^{5}$ The Active People Survey (APS) was a survey conducted by Sport England in order to measure the number of adults taking part in sport across England.
} 
costs of opening our doors, and that's an interesting dilemma going forward.”

(Interviewee J)

These myriad of factors and issues, added to the burgeoning spectre of funding shortfalls, have led to a ramping up of efforts to identify and secure alternate methods of funding. The research interviews continued along this investigative path to identify and evaluate these.

\section{Alternative Revenue Streams - Types, Accessibility, Benefits \& Drawbacks}

All governing bodies interviewed reported that they had searched exhaustively for new revenue streams so as to have more freedom in deploying their resources. A number of alternative revenue generators were highlighted, with some being more popular than others. These alternative revenue streams, as well as their popularity among the governing bodies, will be presented below.

\section{Sponsorship}

In line with the appreciation the topic has received within academic circles, sponsorship was the first 'alternative’ source of income discussed by all interviewees. All interviewees mentioned sponsorship as a current income source, while greater success was identified at a regional rather than national level, possibly because it is simpler to segment the targeted participants for partners more accurately (Irwin, 1995; Pappu \& Cornwell, 2014). If fact it was argued that local clubs could themselves secure substantially more sponsorship income from sponsors from the area than the NGBs were able to on a national level. Despite its popularity among the governing bodies, however, it is worth underlying that only one reported a significant amount of their 
funding was sourced from sponsorship, with the remaining 12 suggesting that sponsorship on a national level was rather challenging, often accounting for less than $10 \%$ of their total income.

'Well our clubs have varying success at the local level - local businesses are interested in sponsorship at a local level, funding local projects and initiatives if those clubs get themselves involved in the community so there have been some clubs successful in getting local sponsorship (by themselves) where it feels more difficult at the national level. It's more difficult for a sponsor to have a return at that level' (Interviewee E)

As the above quote suggests, the coherent theme that emerged from the discussion on sponsorship is that the changing nature of relationships from philanthropic corporate donors to mutually beneficial partnerships is now evident in the agreements made (Herrmann et al., 2016). As a result, the burden of proof in terms of both potential and end results now fall on the sport itself, increasing the need to improve competencies such as customer relationship management, to deal with commercial partners and provide evidentiary support for sponsorship arrangements, thus creating a more onerous and potentially fractious relationship (Misener \& Doherty, 2014). A further issue identified was the external pressures that sponsors and/or broadcasters may bring to bear that may in time alter the sport itself (Farrelly, 2010).

'One of difficulties is that it's less appealing (to sponsors) because it doesn't have its own Paralympic presence. That means I need more people in my team to try to sell sponsorship, while explaining the sport, how it's played and who is 
following it to sponsors. That means they need to work double in the hopes of achieving something' (Interviewee J)

As this quote illustrates, small to medium sized governing bodies can encounter significant difficulties when looking to attract sponsorship, especially in the absence of consistent and far reaching media coverage or major event (e.g. Olympic or Paralympic) exposure. Add to this potential sponsors' increasingly risk averse nature with higher sensitivity to scandal or negative association, and a less philanthropic approach requiring quantifiable results as a product of their investment through significant brand exposure (Wilson, et al., 2011), the burden upon governing bodies has become too great to employ the resources (human, financial and time) needed to create a significant funding stream from this avenue.

\section{Business and Community Partnerships}

When the effort to agree on a sponsorship agreement does not work, an attempt to build a different type of relationship with local partners was mentioned by ten NGBs. Governing bodies have expanded their search for additional funding by seeking to create a symbiotic relationship with non-sport organisations to use external funding to meet the different aims of both stakeholders. These might include engagement, reciprocity and friendship to bring communities together (Misener \& Doherty, 2012), as the quote below illustrates.

'We are knocking on a lot of doors of companies with those budgets for Corporate Social Responsibility.' (Interviewee D) 
This might be of interest to corporations seeking to delivering their corporate social responsibility aims (Smith \& Westerbeek, 2007), as the above quote suggests. Whilst this can be seen as a valuable well from which to draw private funds, in addition to being variable with geography and demography, this stream will be subject to the economic fluctuations of the potential partner. The sport will also need to be able to evidence the positive impacts such a partnership would generate, which the interviewees suggested that can prove challenging. As it was argued by the interviewees, only three NGBs are currently collecting a maximum of 5\% of their total income from these partnerships, with the remaining seven that try to engage in these partnerships often failing to secure any funding.

\section{Corporate Days}

An additional creative and lucrative way to engage with companies and generate extra income mentioned by three interviewees involves taking advantage of the team aspect or challenging nature of the sport, by creating competitions specifically for business or by offering companies the experience of the sport designed to build team spirit and soft skills.

'We've always run an effective corporate event day and the new participation (competition) program is an extension of that so that's a new revenue stream...We basically give work colleagues the chance to work in teams and get a sense of what our athletes feel when they do it (the sport). It pays well and we get very good feedback from the companies that have tried it so far' (Interviewee B) 
Although this revenue stream may prove a fruitful one, despite the administrative costs that may be incurred through laying on additional competitions, not all sports have characteristics that appeal to companies (e.g. individual sports), or lend themselves to be undertaken on a casual, unskilled or inexperienced basis to any great degree of enjoyment or success.

\section{Philanthropy and Donations}

Apart from seeking a partnership with companies, five governing bodies suggested that they often appeal to charitable organisations for support, or find favour from interested individuals in the form of donations or bequests, as the following quote suggests.

'The sport has benefitted from a very generous private donor who has put in a large sum of his own money for his own reasons and that has meant that the male team has been single-handedly funded after central funding was removed. He is a former athlete himself who does it because he truly loves the sport and that it why he's supported them and covered all their expenses' (Interviewee D)

Three of the interviewees argued that the donors are former athletes who demonstrate their passion for the sport and appreciation of the NGBs' work through their support. It was nevertheless suggested that the success rate of such appeals for support was not high. According to interviewees, sports that are known to engage underprivileged or disabled participants have a greater chance of success in attracting charitable support, as well as those organisations that are seen to be serving the society or benefitting the national interest. 


\section{Facility Ownership}

Apart from seeking support, NGBs have also begun to examine the possibilities of generating income through event hosting and management. Four of the governing bodies interviewed had invested in playing facilities that they could use to stage events to generate revenue through ticket and catering sales, as well as renting out to other organisations, as the following quote illustrates.

'We have built our first purpose built facility that is a game changer for us...having a catering partner and leasing a clubhouse... That's now an income generator' (Interviewee G)

Whilst this has a positive revenue diversification aspect to it, the large initial capital requirements and ongoing maintenance and insurance costs associated with this method suggest that only the wealthier governing bodies will be able to achieve this. This has been discussed in the context of professional sport finances, where facility ownership has been shown to be a large determinant of an organisations value (Miller, 2009). Also, more informally practised sports that do not require facilities, such as rambling, orienteering or snow sports could find it challenging to take advantage of this stream.

\section{Event Levy and Hosting}

Moreover, six governing bodies reported that they held flagship national participation events where they could focus their marketing and sponsorship efforts, charge entry fees and generate revenue through merchandising sales to support their financial condition. 
there is less casual play than other sports such as swimming or running etc. Because it's a team sport, it lends itself to more straightforward capture of registrations' (Interviewee B)

According to the interviewees, these annual national events started less than five years ago, with two of the NGBs hosting their first event only two years ago. While planning and managing these events could entail administrative costs and potential risks, the interviewees presented event hosting as lucrative, suggesting that the income generated through them outweighs any additional cost. One Interviewee (B) suggested that due to the success of their event hosting, they were even considering expanding their portfolio of events to international exhibition games, inviting the US teams and athletes to participate. It could be argued that the enthusiasm by which these events were presented by these six NGBs, as well as the complete lack of noting any problems that may have occurred while planning and hosting them could be due to the novelty of this revenue stream. In a similar vein to facilities ownership, the organisation must balance the projected revenues with costs of laying on an event and renting the facilities, when they do not own them, which might prove challenging for smaller governing bodies. Moreover, the quality of the event must be guaranteed to encourage regular participation and repeatability (Wicker \& Breuer, 2014), while taking into consideration that such events might not appeal to all sports (e.g. informally practised sports).

\section{Member Registrations}

Another avenue the NGBs have explored was to introduce charging of annual membership fees to the athletes, coaches and officials of their sports, often providing associated benefits, such as event entry or insurance coverage in return, as Interviewee 
A explained.

'We've just kicked off individual registration. So every player/coach/official within sanctioned competitions will need to be individually registered. We realised central funding is shrinking and we needed to find another avenue' (Interviewee A)

This income source was explored by the majority of the NGBs (11 out of 13), who argued that charging their members was not their preferred income source and was often met with displeasure from their members. The negative aspects of charging a membership fee for a previously free-access sport, such as member protests and making the sport unaffordable to some participants could outweigh the benefits. This is especially true for bodies that had relatively low numbers of members, where the fees generated negligible sums in relation to the extra administrative costs or the body's total costs. Wicker (2011) found that the willingness to pay for access depended entirely on whether there was already a fee in place, as well as the levels of income, education and performance. This suggests that the success and impact of any fee imposition will depend on the sport's participant demographics, as well as on any efforts the NGBs make to offer something in return for the membership fee, as it will be discussed below.

\section{Education Programs and Certification}

Interviewee D argued that an additional profitable revenue stream was being explored by their employer. The governing body has been organising, delivering and charging for educational and technical instruction for improved performance, certification of performance and accreditation to teach, supervise or coach. 
'The biggest generator outside of government is from education. Which means if you want to learn how to improve your technique, or to coach, or be an instructor there are levels of qualification. Likewise, if you want to be an official, we run courses to do those certificates. That's a big generator' (Interviewee D)

This educational programme was being offered to non-members for a full fee, and to already existing members for a discounted fee, as a response to the criticism they received when the membership fees were introduced. While Interviewee D argued that these educational programmes were a big success for the NGB, the ability of a body to take advantage of this stream depends on its characteristics. This stream would work best in sports that are technical in nature, such as weightlifting, have a safety aspect such as mountaineering, or where participants wish to demonstrate improved performance levels amongst peers. Examples such as junior swimming certificates or coloured belt attainment in martial art sports could also apply here. At the same time, this scheme might not work for informally practised sports, such as rambling or orienteering.

What was evident through the interviews with the NGBs is that the avenues they were exploring to secure additional funding have not always been lucrative, despite their efforts. In fact, all NGBs interviewed claimed that the funds they collected often fail to cover the needs and expenses of their athletes, and as a result, teams and individual participants are responsible and expected to fund their own activities, normally through some of the aforementioned streams on a more micro basis, such as personal or team 
sponsorship.

'A lot of the performance side is funded by the players themselves. Virtually all self-funded. When an athlete wants to be serious about the sport, they find their own sponsor, their own equipment, their own support' (Interviewee J)

This can then lead to inconsistency across the sport, creating issues with competitive balance between participants, the provision of the sport on a geographical basis and the long term development of both mass participation and elite aspects (Miller, 2006). In other words, this contradicts the main objectives of the government policy that aimed at increasing sport participation for all (HM UK Government, 2015).

Taking all the above into consideration, it can be argued that there appears to be no 'one-size fits all' approach to alternative revenue streams, as the sporting characteristics, participant numbers and social profile of a sport all dictate which streams are likely to be most fruitful, while the specific mix of revenues, as well as the longer term impact on the sport in terms of participation and development, must also be considered.

\section{Main Findings}

Whilst there has been a significant body of research carried out on the challenges faced by non-profit organisations when it comes to funding and a plethora of studies regarding broadcast, media and commercial earning capabilities of large sporting organisations, there remains a gap when it comes to focus on smaller and non-commercialised sport NGBs. These are organisations that find themselves outside the mainstream, headlinemaking national sporting consciousness and, coupled with the recent, relentless drive towards austerity by the Government, their plight with regards to financing has become 
more pressing. This research sought to fill this gap with a broad overview of those difficulties, contrasting them to the benefits of central Government funding and the dynamics of this relationship of dependency. In addition, interviewees from organisations with vastly differing profiles proffered potential solutions that had not been covered en masse by previous research. Sponsorship has often been mooted by literature to be the holy grail of sports funding, but this research sought to look at this avenue in the context of the smaller, non-commercialised or niche sport organisation that has rarely been the focus of such studies.

\section{Policy and Management Implications}

What this means for centrally funded sport NGBs is that in order to be able to cover core, project and infrastructure costs in their entirety, a number of successful initiatives would need to be undertaken. A further refinement of this idea could be that revenue generating schemes should be matched in characteristics to its expenditure. In other words, core running costs should be covered by consistently achievable and predictable revenues such as membership fees, whereas one-off or special costs such as new infrastructure should be met through more irregular fund raising activities, for instance event hosting or exhibition matches. That would leave participation endeavours, often encouraged by government at local or national organisations, to be funded through partnerships or grants at those levels. In short, interested parties would be obliged to pay for their associated objectives.

A second implication, raised largely by the enforced focus on cost reduction and efficiency, would be the creation of cross-sport forums to facilitate discussion and idea sharing to achieve both financial and operational excellence. These could be hosted by Sport England who would then, ultimately, take on the role of a centre of expertise, 
eradicating replication and wastage whilst ensuring cross sector adoption of best practices. Benchmark practices and lessons could be then learned by larger, more successful NGBs, in order for knowledge sharing and overall development to be encouraged, as well as for the adoption of new technologies, which are currently missing from the NBGs’ practice, to be aided. Taken to its rational end, this may result in a shared service approach to many functions that currently each governing body creates and pays for itself.

\section{Limitations and Future Research}

That being said, this research was limited by the relatively low sample number of governing bodies that took part, and would have benefitted by an even larger cross section of the spectrum of size, scope and sporting characteristics involved. This would have allowed not only for greater validity and reliability of its findings, but also for the chance to investigate applying the alternative revenue solutions of one organisation to another with different aims or profile. Allied to this limitation, the perspective of the government, specifically Sport England, would have added greatly to the findings as it may have shone further light on the future of Government funding levels and processes. A second limitation is to be found in the breadth of subject inquiry, as this limited its ability to delve deeper into any one stream to uncover the mechanics required to make these a successful tool, or even more usefully, act as a template to match potential funding streams with characteristics of the governing bodies to make the process more efficient and effective overall. A future possible quantitative approach to investigating the relationship between quantifiable attributes of organisations such as member numbers, demographics or geography and their ability to be successful in raising funds through different methods could assist in such an effort. Thirdly, the research would 
have benefitted by the inclusion of sports that do not currently benefit from Government funding. Those sports that already operate on a privately funded basis, either as a result of the loss of central funding or by choice, would have offered an interesting contrast to those interviewed, and almost provided a 'future view' of conditions required to successfully become self-sufficient, as encouraged by the U.K. Government.

\section{Conclusions}

This study allowed for some insight to the dynamics of the relationship between the funder / government and the funded, suggesting that aligning views and objectives does not always occur without friction, with the majority of the interviewees expressing discontent regarding their high dependency from the Government and their consequent lack of autonomy. Unlike earlier studies on the matter (Slack \& Hinings, 1992; Horch, 1994; Vos et al., 2011) where this high dependency relationship is discussed, the findings of this research allowed for emphasis to be placed on the views of the NGBs who presented this lack of autonomy with not such bright colours. This discontent did not, nevertheless, decrease their fears and uncertainty for a future without this central funding, while acknowledging that such a future is afoot.

What this research has found is that none of the 13 governing bodies involved could be categorised in the same way, with vastly different stakeholder aims, funding needs, governance frameworks and abilities to effect change. For example, some of the NGBs were primarily concerned with looking after existing membership and some with growing membership. Some had leveraged the need for Sport England funding to achieve reforms in governance, yet some remained hamstrung by the demographics of their membership manifested in resistance to change. Some had benefitted by a willingness to pay by a large number of participants, or the generosity of 
philanthropists, whereas others faced issues of monetizing participation due to the informal nature of the sport.

Whilst this made comparisons between them difficult to draw, it also highlights the need for a flexible, innovative way of approaching their funding if government contributions decline or disappear, as Brooks (2000) argued. This study found that no single method of funding could likely be applied to every sport or governing body, but also, and equally importantly, that it was unlikely a sport could rely on any one avenue to replace the government resources. Not only this, but evidence was also uncovered that the specific mix of revenue-raising endeavours impacted the governing body's own functioning, and its ability to raise capital from other sources, as Hardina (1993) and Froelich (1999) argued for multi-stream funded organisations. As a result, increasing the portfolio of funders might subject the NGBs to additional future challenges and risks (Kingma, 1993). Finally, contrary to previously held perceptions (Jensen \& Cobbs, 2014; Herrmann et al., 2016), sponsorship was found to be considerably less useful than many other methods as a result of the current domination of a few sports, decreasing philanthropic desire on the corporate part and increasing accountability for investment on lower sponsorship budgets. 


\section{References}

Aharoni, Y., Maimon, Z. \& Segev, E., 1981. Interrelationships between environmental dependencies: A basis for tradeoffs to increase autonomy. Strategic Management Journal, 2(2), 197-208.

Anheier, H. K., Toepler, S. \& Sokolowski, S. W., 1997. The implications of government funding for non-profit organizations: three propositions. International Journal of Public Sector Management, 10(3), 190-213.

Aschauer, D. A., 1989. Does public capital crowd out private capital?. Journal of monetary economics, 24(2), 171-188.

Bielefeld, W., 1992. Non-Profit Funding Environment relations: theory and application. Voluntas, 3(1), 48-70.

Brooks, A. C., 2000. Is There a Dark Side to Government Support for Nonprofits?. Public Administration Review, 60(3), 211-218.

Carey, G. E. \& Braunack-Mayer, A., 2009. Exploring the effects of government funding on community- based organizations: ‘ top- down’ or ‘ bottom- up’ approaches to health promotion?. Global Health Promotion, 16(3), 45-52.

Carrigan, M. \& Carrigan, J., 1997. UK Sports Sponsorship:Fair Play or Foul?. Business Ethics: A European Review, 4, 6(2), 59-64.

Coaffee, J., 2008. Sport, culture and the modern state: emerging themes in stimulating urban regeneration in the UK. International Journal of Cultural Policy, 14(4), 377397.

Collins, M., 2010. From 'sport for good' to ‘sport for sport's sake' - not a good move for sports development in England?. International Journal of Sport Policy and Politics, 2(3), 367-379.

Copeland, R., 1996. Understanding the sport sponsorship process from a corporate perspective. Journal of Sport Management, 10(1), 32-48. 
Department for Culture Media and Sport, 2013. Sport England Spending Round Letter. [Online] Available at: https://www.gov.uk/government/uploads/system/uploads/attachment_data/file/2105 70/Sport_England-Letter.pdf [Accessed 2303 2016].

Doherty, A., 2009. The Volunteer Legacy of a Major Sport Event. Journal of Policy Research in Tourism, Leisure and Events, 1(3), 185-207.

Enjolras, B., 2002. The commercialization of voluntary sport organizations in Norway. Nonprofit and voluntary sector quarterly, 31(3), 352-376.

Farrelly, F., 2010. Not Playing the Game: Why Sport Sponsorship Relationships Break Down. Journal of Sport Management, 24(3), 319-337.

Fisher, B., Turner, R. K. \& Morling, P. 2009. Defining and classifying ecosystem services for decision making. Ecological economics, 68(3), 643-653.

Froelich, K., 1999. Diversification of revenue strategies: evolving resource dependence in nonprofit organizations. Non-Profit and Voluntary Sector Quarterly, 28(3), 246268.

Garrett, R., 2004. The response of voluntary sports clubs to sport England’s lottery funding: Cases of compliance, change and resistance. Managing Leisure, 9(1), 1329.

Green, M., 2006. From ' Sport for All' to Not About ' Sport' at All?: Interrogating Sport Policy Interventions In the United Kingdom. European Sport Management Quarterly, 6(3), 217-238.

Green, M., 2007. Olympic glory or grassroots development?: Sport policy priorities in Australia, Canada and the United Kingdom, 1960 - 2006. The International Journal of the History of Sport, 24(7), 921-953. 
Green, M. \& Collins, S., 2008. Policy, Politics and Path Dependency: Sport

Development in Australia and Finland. Sport Management Review, 11(3), 225-251.

Grix, J. \& Carmichael, F., 2012. Why do governments invest in elite sport? A polemic. International Journal of Sport Policy and Politics, 4(1), 73-90.

Grix, J. \& Houlihan, B., 2014. Sports mega-events as part of a nation's soft power strategy: The cases of Germany (2006) and the UK (2012). The British journal of politics and international relations, 16(4), 572-596.

Hall, C. M., 2006. Urban entrepreneurship, corporate interests and sports mega-events: the thin policies of competitiveness within the hard outcomes of neoliberalism. The Sociological Review, 54(s2), 59-70.

Hardina, D., 1993. The Impact of Funding Sources and Board Representation on Consumer Control of Service Delivery in Organisations Serving Low-Income Communitites. Nonprofit Management and Leadership, 4(1), 69-84.

Herrmann, J. L., Kacha, M. \& Derbaix, C., 2016. “I support your team, support me in turn!”: The driving role of consumers' affiliation with the sponsored entity in explaining behavioral effects of sport sponsorship leveraging activities. Journal of Business Research, 69(2), 604-612.

Hillman, A. J., Withers, M. C. \& Collins, B. J., 2009. Resource Dependence Theory: A Review. Journal of Management, 35(6), 1404-1427.

HM UK Government, 2015. Sporting Future: A New Strategy for an Active Nation. [Online] Available at: https://www.gov.uk/government/uploads/system/uploads/attachment_data/file/4866 22/Sporting_Future_ACCESSIBLE.pdf_[Accessed 2203 2016].

Horch, H. D., 1994. On the socio-economics of voluntary organisations. Voluntas: international journal of voluntary and nonprofit organizations, 5(2), 219-230. 
Houlihan, B. \& Green, M., 2009. Modernization and sport: the reform of sport England and UK sport. Public Administration, 87(3), 678-698.

Irwin, R. L., 1995. A Model for Screening Sport Sponsorship Opportunities. Journal of Promotion Management, 2(3-4), 53-70.

Jensen, J. A. \& Cobbs, J. B., 2014. Predicting return on investment in sport sponsorship. Journal of Advertising Research, 54(4), 435-447.

Kavetsos, G. \& Szymanski, S., 2009. From the Olympics to the grassroots: What will London 2012 mean for sport funding and participation in Britain?. Public Policy Research, 16(3), 192-196.

Kingma, B., 1993. Portfolio Theory and Nonprofit Financial Stabilit. Nonprofit and Voluntary Sector Quarterly, 22(2), 105-119.

Kramer, R. M., 1981. Voluntary agencies in the welfare state. Berkeley: University of California Press.

Krashinsky, M., 1990. Management Implications of Nonprofit Organisations: Views from the United States and Canada. Nonprofit Management and Leadership, 1(1), $39-53$.

Lasby, D. \& Sperling, J., 2007. Understanding the capacity of Ontario sports and recreation organizations. Toronto: Imagine Canada.

Lee, N. \& Lings, I., 2008. Doing Business Research. London: Sage.

Lester, R. H., Hillman, A., Zardkoohi, A. \& Cannella, A. A., 2008. Former government officials as outside directors: The role of human and social capital. Academy of Management Journal, 51(5), 999-1013.

Manoli, A. E. 2015. Promoting corporate social responsibility in the football industry. Journal of Promotion Management, 21(3), 335-350 
Manoli, A. E. \& Hodgkinson, I. R. 2017. Marketing outsourcing in the English Premier League: the rights holder/agency interface. European Sport Management Quarterly, 17(4), 436-456.

Markowitz, H. M., 1991. Foundations of Portfolio Theory. Journal of Finance, 46(2), 469-477.

Miller, L. E., Kruger, E. J. \& Guass, M. S., 1994. Nonprofit Boards and Perceptions of Funding. Nonprofit Management and Leadership, 5(1), 3-17.

Miller, P. A., 2006. Revenue sharing in sport leagues : the effects on talent distribution and competitive balance. Journal of Sports Economics, 8(1), 62-82.

Miller, P. A., 2009. Facility Age and Ownership in Major American Team Sports Leasues: The Effect on Team Franchise Values. International Journal of Sport Finance, 4(3), 176.

Mintel (2011) Leisure review. London: Mintel Group Limited.

Misener, K. \& Doherty, A., 2012. Connecting the community through sport club partnerships. International Journal of Sport Policy and Politics, 4(2), 243-255.

Misener, K. \& Doherty, A., 2014. In support of sport: Examining the relationship between community sport organizations and sponsors. Sport Management Review, 17(4), 493-506.

Mitchell, V. W., 1994. Using industrial key informants: Some guidelines. Journal of the Market Research Society, 36(2), 139-145.

O'Regan, K. \& Oster, S., 2002. Does Government Funding Alter Nonprofit Governance? Evidence from New York City Nonprofit Contractors. Journal of Policy Analysis and Management, 21(3), 359-379. 
Pappu, R. \& Cornwell, T. B., 2014. Corporate sponsorship as an image platform: understanding the roles of relationship fit and sponsor-sponsee similarity. Journal of the Academy of Marketing Science, 42(5), 490-510.

Pfeffer, J. \& Salancik, G. R., 1978. The external control of organizations : a resource dependence perspective. New York, London: Harper \& Row.

Ramchandani, G., Davies, L. E., Coleman, R., Shibli, S., \& Bingham, J., 2015. Limited or lasting legacy? The effect of non-mega sport event attendance on participation. European Sport Management Quarterly, 15(1), 93-110.

Sam, M. P., 2009. The Public Management of Sport. Public Management Review, 11(4), 499-514.

Saunders, M., Lewis, P. \& Thornhill, A., 2012. Research Methods for Business Students. London: Pearson.

Slack, T. \& Hinings, B., 1992. Understanding change in national sport organizations: An integration of theoretical perspectives. Journal of sport management, 6(2), 114132.

Sloman, J., 1994. Economics. Hemel Hempstead: Harvester Wheatsheaf.

Smith, A. C. \& Westerbeek, H. M., 2007. Sport as a Vehicle for Deploying Corporate Social Responsibility. The Journal of Corporate Citizenship, Volume 25, 43-54.

Sport England, 2013. 2013-17 Whole Sport Plan Investments. [Online]

Available at: https://www.sportengland.org/our-work/national-governingbodies/sports-we-invest-in/2013-17-whole-sport-plan-investments/ [Accessed 1204 2016].

Taylor, M. \& O'Sullivan, N., 2009. How should national governing bodies of sport be governed in the UK? An exploratory study of board structure. Corporate governance: an international review, 17(6), 681-693. 
Tolbert, P. S., 1985. Institutional Environments and Resource Dependence: Sources of Administrative Structure in Institutions of Higher Education. Administrative Science Quarterly, 30(1), 1-13.

Toohey, K., 2008. The Sydney Olympics: Striving for legacies-overcoming short-term disappointments and long-term deficiencies. The International Journal of the History of Sport, 25(14), 1953-1971.

Turner, D., 2013. The civilized skateboarder and the sports funding hegemony: a case study of alternative sport. Sport in Society, 16(10), 1248-1262.

UK Government, 2015. UK Government. [Online]

Available at:

https://www.gov.uk/government/uploads/system/uploads/attachment_data/file/4866 22/Sporting_Future_ACCESSIBLE.pdf [Accessed 1001 2016].

UK Government, 2015. UK Government Autumn 2015 Spending Review. [Online] Available at: https://www.gov.uk/government/uploads/system/uploads/attachment_data/file/4797 49/52229_Blue_Book_PU1865_Web_Accessible.pdf [Accessed 1301 2016].

Ulrich, D., \& Barney, J. B., 1984. Perspectives in organizations: resource dependence, efficiency, and population. Academy of Management Review, 9(3), 471-481.

Van Brummelen, H., 1993. The Effects of Government Funding on Private Schools: Appraising the Perceptions of Long-Term Principals and Teachers in British Columbia's Christian Schools. Canadian Journal of Education, 18(1), 14-28.

Vos, S., Breesch, D., Késenne, S., Van Hoecke, J., Vanreusel, B. \& Scheerder, J., 2011. Governmental subsidies and coercive pressures. Evidence from sport clubs and their resource dependencies. European journal for sport and society, 8(4), 257-280. 
Weisbrod, B. A., Handler, J. F. \& Komesar, N. K. 1978. Public interest law: An economic and institutional analysis. Berkeley: University of California Press.

Wicker, P., 2011. Willingess to Pay in Nonprofit Sports Clubs. International Journal of Sport Finance, 6(2), 155-169.

Wicker, P. \& Breuer, C., 2011. Scarcity of resources in German non-profit sport clubs. Sport management review, 14(2), 188-201.

Wicker, P. \& Breuer, C., 2014. Examining the Financial Condition of Sport Governing Bodies: The Effects of Revenue Diversification and Organizational Success Factors. International Journal of Voluntary and Nonprofit Organizations, 25(4), 929-948.

Wicker, P., Breuer, C. \& Hennigs, B., 2012. Understanding the interactions among revenue categories using elasticity measures : evidence from a longitudinal sample of non- profit sport clubs in Germany. Sport Management Review, 15(3), 318-329.

Wilson, B., Westberg, K. \& Henseler, J., 2011. Managers' perceptions of the impact of sport sponsorship on brand equity which aspects of the sponsorship matter most?. Sport Marketing Quarterly, 20(1), 7-21.

Zimmerman, A., Raisch, S. \& Birkinshaw, J., 2015. How Is Ambidexterity Initiated? The Emergent Charter Definition Process. Organization Science, Articles in Advance, 1-21. 